VII Congresso Brasileiro de Informática na Educação (CBIE 2018)

Anais do XXIX Simpósio Brasileiro de Informática na Educação (SBIE 2018)

\title{
A rota da aprendizagem: seriam os games uma via?
}

\author{
Luis Henrique Sforzin Pazzini \\ Departamento de Educação \\ sociometria@gmail.com \\ Gilda Helena B. de Campos \\ Coordenação Central de Educação a distância - CCEAD PUC-Rio \\ gilda@ccead.puc-rio.br \\ Pontifícia Universidade Católica do Rio de Janeiro \\ Rua Marquês de São Vicente, 225 - Gávea - Rio de Janeiro - RJ - Brasil
}

\begin{abstract}
Resumo - A reflexão sobre o futuro dos sistemas de educação deve estar fundamentada nas novas mutações contemporâneas pelas quais passa a relação com o saber (Lévy, 2014). No panorama da cultura digital, Heinsfeld e Pischetola (2017) esclarecem que a competência docente se constitui como um desafio de incorporar as novas tecnologias, se apropriar delas para promover novas práticas e relações mais coerentes com a postura de incentivar a aprendizagem, de provocar o pensamento e a reflexão. É o início de um desafio. Partindo da apropriação da reflexão acerca do uso da gamificação, investigar os games pelo prisma conceitual de Petry (2017), tendo como objetivo analisar se um game do tipo mundo aberto possibilita uma "boa aprendizagem" de acordo com os dezesseis princípios de James Paul Gee (2009).
\end{abstract}

Palavras-chave: Educação, games, gamificação, cultura digital, tecnologias midiáticas.

\section{Introdução}

Vivencia-se uma cultura digital experimentada de diferentes maneiras por docentes e alunos. Neste contexto, André Lemos (2009) se aproxima de Lévy (2014) ao concordar que cultura digital e cibercultura são sinônimos, e que cibercultura está relacionada com advento da microinformática, que situa as tecnologias digitais na dimensão da comunicação, possibilitando uma transformação cultural. Estes desafios, dentro da relação entre cultura digital e educação inovadora, ensejam refletir sobre usos e opções de tecnologias midiáticas para serem trabalhadas na educação. E dentre estas opções, estão os games. É preciso esclarecer que este trabalho não pretende se debruçar na gamificação enquanto proposta de pesquisa, mas sim investigar os games enquanto objetos dentro do escopo da aprendizagem. Vale ressaltar que este projeto lança mão de algumas relações teóricas produzidas no campo da gamificação para delimitar o percurso de pesquisa. Por isso, cabe aqui uma breve contextualização sobre a importância da gamificação como ramo de pesquisa e sua contribuição para pensar as tecnologias educacionais, tais como os games (jogos digitais). Há entre os pesquisadores um consenso que o termo aparece em 2002 com Nick Pelling através de seus esforços para atrair clientes para indústrias (Martens, Mueller, 2016). Desde então seguindo ignorado até 2008, quando reaparece com força na área do marketing e das Ciências da Computação.

\section{Objetivos}

Na tentativa de aproveitar a perspicácia a que chegou a reflexão crítica no campo da gamificação, este artigo nasce de relações teóricas desenhadas a partir das fronteiras 
conceituais que o objeto game $e^{l}$ pode assumir, partindo de perspectivas de análise que conjuguem três aspectos da problematização acima contextualizada, a saber: (I) incluir o olhar dos usuários envolvidos no processo de pesquisa, (II) observação criteriosa acerca do design de jogo e, por fim, (III) rigor científico sobre a produção de evidências que possam servir de margem de interpretação para resultados práticos sobre a aprendizagem. Logo, lança mão de relações teóricas que dão instrumentos para construir e analisar situações empíricas em educação. Seguindo o proposto acima sobre as reflexões acerca da gamificação, foram adotados os recentes estudos de Petry para contemplar o primeiro aspecto destacado. Desse modo, emprega-se neste projeto a abordagem teórica de Petry para discutir a perspectiva ontológica do jogo digital e apresentar a estrutura conceitual deste projeto baseada em um compartilhamento de diferentes visões do campo cultural do games. Encerra-se esta primeira parte na tessitura de possíveis relações com abordagens de outros pesquisadores da área das tecnologias digitais. Cabe observar que os games são um tipo de mídia, e:

De um ponto de vista sociológico as mídias são ferramentas, suportes ou veículos que viabilizam trocas linguísticas e simbólicas entre os homens, e tornam possíveis a virtualização dessas trocas, ou seja, seu deslocamento no tempo e/ou espaço. (Assis et al., 2013, p. 80)

Esse contexto permite pensar um conceito que abarque uma identidade compartilhada, fazendo presentes nesta reflexão os três atores ligados a este objeto digital cultural, a saber: jogadores, desenvolvedores e pesquisadores. (Petry, 2017). O autor também destaca o caráter multidisciplinar dos games, que não constituem monopólio de nenhuma área de saber, ou seja, as transcende, pois é um objeto cultural digital interdisciplinar ou transdisciplinar. Para Petry, por mais que games possuam código fonte, e demandem programação, não podem ser tratados simplesmente como pertencentes ao campo dos softwares. Por isso, Petry propõe uma alternativa conceitual que conjugue os aspectos apontados acima através dos relatórios da IGDA (IGDA é a Associação Internacional de Desenvolvedores de Games, sediada nos Estados Unidos e organizada em capítulos pelo mundo). Partindo dos relatórios da IGDA conjugados por uma reflexão filosófica ontológica, Petry inclui em sua delimitação conceitual quatro elementos compartilhados pelo campo cultural dos games:

- Conceito que cubra epistêmica e materialmente o game, que consiste em descrever a complexidade e amplitude híbrida dos games;

- Metodêutica, que é o acesso analítico ao objeto que permita compreender seus fundamentos e possibilidades de aplicação;

- Game como um campo diversificado de extensão prática, ou seja, o impacto do objeto dentro das diferentes áreas da cultura e da sociedade;

- Entendimento como um objeto digital da cultura, mas diferente das demais mídias tradicionais.

É possível vislumbrar uma outra relação importante entre o conceito de Petry e a reflexão teórica de James Paul Gee sobre os games, e que enseja uma proposta de investigação empírica no campo da educação. Apoiando-se em evidências encontradas pelas Ciências Cognitivas, Gee (2003) ressalta que bons games incorporam princípios de aprendizagem. Isso porque as disciplinas podem ser entendidas como jogos, pois constituem atividades estruturadas a partir de regras, em que participantes assumem identidades, buscam objetivos, utilizam ferramentas próprias, compartilham linguagens e imergem em

\footnotetext{
${ }^{1} \mathrm{O}$ termo game daqui para frente empregado neste projeto se refere aos jogos eletrônicos das principais plataformas: PSN, XBOX, Windows, Steam, Nintendo, entre outras.
} 
um sistema artificial de ações. Gee concorda que os games conduzem o jogador a usar eficazmente as regras do jogo, e a se familiarizar com ambiente (cenário) e possibilidades de ação. Gee mostra como disciplinas se aproximam dos games em suas características e elementos constitutivos. Se uma disciplina pode ser pensada como instrumento sofisticado de aprendizagem, então os games também possuem esses predicados. Gee (2009) identifica dezesseis princípios da boa aprendizagem, são eles: identidade; interação; produção; riscos; customização; agência; boa ordenação dos problemas; desafio e consolidação; "na hora certa" e "a pedido"; sentidos contextualizados; frustração prazerosa; pensamento sistemático; exploração, pensamento lateral, revisão dos objetivos; conhecimento distribuído; equipes transfuncionais e performance anterior à competência. Observa-se que a abordagem de Gee (2003) envolve dois elementos compartilhados do campo cultural dos games delineados por Petry (2017): o aspecto epistemológico e o metodêutico, pois Gee (2003) relaciona o conceito de jogo em analogia com as disciplinas escolares e ainda descreve dezesseis princípios que permitem o acesso analítico aos games enquanto recurso para aprendizagem (Gee, 2009).

\section{Open World Games : Por que optar pelos Open World Games?}

Para responder esta pergunta é preciso contemplar o segundo aspecto citado acima sobre a reflexão crítica acerca da gamificação, ou seja, aplicar uma observação mais detalhada sobre o design de jogo. Como destaca Brown (2015), os chamados Open World Games envolvem uma boa gama de interpretações e muitos títulos podem ser classificados nesta categoria. Muitos gêneros (de jogo) que permitam o gamer vagar por áreas indiscriminadamente podem se encaixar na descrição de jogos mundo aberto.Muitos o consideram um estilo que inova em uma jogabilidade inspiradora. Brown (2015) define jogos mundo aberto como aqueles que rompem com a estrutura convencional baseada em fases, levels, conferindo ao gamer a liberdade de explorar o jogo sem um objetivo específico. Paredes invisíveis oferecem um cenário sem barreiras, preenchido por inúmeras atividades concomitantes constroem um leque vasto de opções para o gamer pensar suas possibilidades de ação e executá-las.Brown esclarece que Sand Box é um estilo de design de jogo que consiste em aplicar inúmeros cenários e sistemas de ação dentro de um jogo, como se operassem minigames dentro de um game, o que amplia o espectro alinear de exploração e traduz um percurso de jogo fora da convencional retidão sequencial de fases. Embora o design sand box possa ter várias características que definem os open world games, ainda assim, existe uma diferença entre o foco principal que cada estilo busca atender como propósito, sendo o primeiro voltado para inserção de minigames dentro de uma game, e o segundo orientado para a exploração irrestrita de cenários. Nota-se que tanto os games do estilo sand box quanto os games open world acabam atingindo resultados próximos, tais como a quebra da estrutura convencional de fases, remoção de objetivo específicos que o personagem tenha que cumprir, jogabilidade alinear entre outros. Por isso, são estilos de design de game que combinam e podem ser empregados juntos na proposta de convecção de um título.

\section{Uma revisão a título de considerações}

Aqui visa-se contemplar o último aspecto proposto pela reflexão acerca da gamificação, em que se busca o rigor científico para confiar em evidências que venham a ser extraídas dos experimentos. Dessa forma, o desenvolvimento futuro deste artigo utilizará método de análise qualitativa baseada na observação direta, através de vídeos e análise das imagens como fonte de informação (Bauer, Gaskell, 2015), realizando translação do 
VII Congresso Brasileiro de Informática na Educação (CBIE 2018)

Anais do XXIX Simpósio Brasileiro de Informática na Educação (SBIE 2018)

material audiovisual coletado e análise de conteúdo de acordo com Bardin (2016). A observação será feita a partir de um roteiro de observação, elaborado de acordo com os princípios da boa aprendizagem de Gee (2009), que serão convertidos em categorias de análise:

- Identidade se refere ao compromisso do jogador em assumir uma identidade em um mundo virtual;

- Interação consiste nas palavras e atos colocados no contexto de interação entre jogador e mundo virtual;

- Produção é a característica que jogadores têm de construir mundos virtuais que eles vivem no game;

- Risco diz respeito à minimização das consequências em relação às falhas, incentivando jogadores a tentar coisas novas;

- Customização é o atributo conferido ao jogador para ajustar o game de acordo com seu estilo de aprender e jogar;

- Agência é sensação de controle sobre o que estão fazendo dentro do game;

- Boa ordenação dos problemas quando desafios anteriores conduzem os jogadores a se aprimorarem para adiante solucionarem desafios mais difíceis;

- Desafio e consolidação é a característica de aplicar rotinas que promovem a perícia no emprego de soluções criativas aos problemas apresentados;

- "Na hora certa" e "a pedido" se refere ao parâmetro de apresentar informações somente quando é necessário e possível seu uso no mundo virtual;

- Sentidos contextualizados se referem ao emprego de termos e palavras sempre os ligando às imagens e ações a que elas se relacionam no game;

- Frustração prazerosa consiste na gradação das situações-problema a serem resolvidos para dar conta da heterogeneidade dos jogadores, não sendo nem fáceis demais nem impossíveis de resolver, mas desafiadoras;

- Pensamento sistemático é quando o game proporciona ao jogador o cálculo das consequências das ações dentro do mundo virtual;

- Pensar lateralmente é quando o game encoraja os jogadores a explorarem minuciosamente detalhes do mundo virtual;

- Conhecimento distribuído se refere ao contexto em que personagens do mundo virtual emprestam habilidades aos jogadores, ou seja, o jogador não precisa saber tudo sobre o game, as habilidades cognitivas necessárias para interação com o mundo virtual ficam distribuídas entre personagem e jogador;

- Equipes transfuncionais são a demanda de que cada jogador deve dominar e cumprir sua função dentro do mundo virtual e se afiliar a outros personagens com outras especialidades no game;

- Performance anterior a competência é a condição que os games oferecem para o jogador ter bom desempenho nas tarefas antes de desenvolver plenamente uma competência;

O próximo passo será, portanto, converter estas características em categorias de análise para a realização do experimento.

\section{Referências}

BARDIN, L. Análise de Conteúdo. São Paulo: Edições 70, 2016.

BAUER, M. W. GASKELL, G. (orgs.). Pesquisa Qualitativa com Texto, Imagem e Som: um manual prático. Rio de Janeiro: Vozes, 2015.

COUTINHO, I., J. Videojogos e aprendizagem: considerações e reflexões sobre as contribuições de James Paul Gee. Barcelona: Portal da Comunicação InCom-UAB, 2001-2015

FREITAS, G. R. A Indústria Criativa dos Jogos Digitais: uma abordagem sociológica. Instituto de Filosofia e Ciências Humanas, UFRS (Universidade Federal do Rio Grande do Sul), 2014.

GEE, J. P. What video games have to teach us about learning and literacy. New York: Palgrave / Macmillan, 2003.

GEE, J. P. Bons videogames e boa aprendizagem. Mary Lou Fulton Institute and Graduate School of Education, Division of Curriculum \& Instruction. 22/05/2009

GEE, James Paul. Bons Vídeos jogos + Boa aprendizagem: coletânea de Ensaios sobre os videojogos e Aprendizagem e a Literária. Portugal: Pedágio, LDA, 2010.

LEMOS, A. Infraestrutura para Cultura Digital: o que é a cultura digital ou cibercultura? in Cultura digital.br. SAVAZONI, R., COHN, S. (org.). Rio de Janeiro : Beco do Azougue, 2009. 
VII Congresso Brasileiro de Informática na Educação (CBIE 2018)

Anais do XXIX Simpósio Brasileiro de Informática na Educação (SBIE 2018)

LÉVY, P. Cibercultura. São Paulo: Editora 34, 2014.

PETRY, L. C. O Conceito Ontológico de Jogo in Jogos Digitais e Aprendizagem - fundamentos para uma prática baseada em evidências. ALVES, L. COUTINHO, I. (org.) São Paulo: Papirus, 2017. 